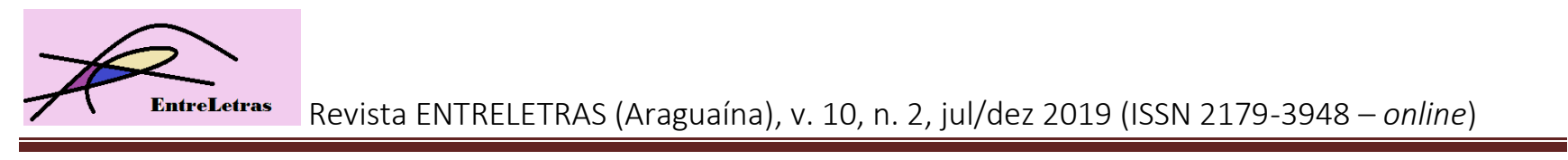

\title{
DUAS DÉCADAS DE AMADURECIMENTO: MARCOS DA LITERATURA INFANTIL BRASILEIRA ENTRE 1960 E 1980
}

\section{TWO DECADES OF MATURING LANDMARKS OF BRAZILIAN CHILDREN'S LITERATURE BETWEEN 1960 AND 1980}

\section{Regina Zilberman ${ }^{1}$}

Resumo: Os primeiros livros brasileiros dirigidos ao público infantil e juvenil apareceram ao final do século XIX, patrocinados pela Livraria Quaresma. A nacionalização e o encorpamento dessa chegaram com Monteiro Lobato, que, em 1921, lançou A menina do narizinho arrebitado. Embora não tenha cessado a produção de novos livros destinados a crianças e jovens durante os anos 1950 e 1960, personagens, cenários escolhidos, temas e enredos permaneciam caudatários do universo imaginário criado por Lobato. A década de 1960 abre com a renovação da poesia, graças a $\mathrm{Ou}$ isto ou aquilo, de Cecília Meireles. No âmbito da narrativa, a renovação ficará por conta de $O$ rei de quase-tudo, de Eliardo França, $O$ reizinho mandão, de Ruth Rocha, História meio ao contrário, de Ana Maria Machado, Flicts, de Ziraldo, Os colegas, de Lygia Bojunga, obras lançadas entre 1969 e 1979, marcando o período de amadurecimento da produção para crianças em nosso país.

Palavras-chave: Cecília Meireles; Eliardo França; Ruth Rocha; Ana Maria Machado; Ziraldo; Lygia Bojunga

Abstract: The first Brazilian books aimed to children and young people appeared in the late
nineteenth century, published by Livraria Quaresma. Their nationalization and growth came with
Monteiro Lobato, who in 1921 launched A menina do narizinho arrebitado. Although new books
never ceased to be produced and published during the 1950s and 1960s, characters, space and
landscape, themes and plots remained subservients to the imaginary universe created by Lobato.
The Sixtieths open with the renewal of the poetry, thanks to Ou isto ou aquilo, from Cecília
Meireles. Within the narrative field, the renewal comes with Eliardo França's O rei de quase-
tudo, Ruth Rocha's O reizinho mandão, Ana Maria Machado's História meio ao contrário,
Ziraldo's Flicts, and Lygia Bojunga's Os colegas, works launched between 1969 and 1979,
marking the maturity of the production for children and youth in our country.

Keywords: Cecília Meireles; Eliardo França; Ruth Rocha; Ana Maria Machado; Ziraldo; Lygia Bojunga

Os primeiros livros brasileiros dirigidos especialmente ao público infantil e juvenil apareceram ao final do século XIX, patrocinados pela modesta Livraria Quaresma. Antes dessa inicia-

\footnotetext{
${ }^{1}$ Professora Associada do Instituto de Letras, da Universidade Federal do Rio Grande do Sul - Porto Alegre, RS, Brasil. E-mail: regina.zilberman@gmail.com.
} 
tiva, predominava a importação de obras europeias, publicadas sobretudo em Portugal. Da sua parte, as poucas editoras nacionais dedicavam-se ao oferecimento de livros destinados à escola, as seletas, que reuniam clássicos da tradição lusófona.

A nacionalização e o encorpamento da produção endereçada a crianças e jovens chegaram com Monteiro Lobato (1842-1948), que, em 1921, lançou, por sua própria editora, A menina do narizinho arrebitado, o primeiro expoente da literatura infanto-juvenil brasileira. Entre aquela data e o ano de sua morte, Lobato abasteceu a moçada com seus livros, ciclo que pode ter-se interrompido, não, porém, sua influência, identificável nos ficcionistas que, cronologicamente, se seguiram a ele, como Francisco Marins (1922), Lúcia Machado de Almeida (1910-2005), Ofélia Fontes (1902), Maria José Dupré (1898-1984).

Embora não tenha cessado a produção de novos livros destinados a crianças e jovens durante os anos 1950 e 1960, personagens, cenários escolhidos, temas e enredos permaneciam caudatários do universo imaginário criado por Monteiro Lobato, resumido no Sítio do Pica-pau Amarelo e seus principais habitantes, como as crianças Pedrinho e Narizinho, os bonecos Emília e Visconde de Sabugosa, as senhoras D. Benta e Tia Nastácia, os animais falantes Quindim e Conselheiro. Além disso, as obras oferecidas às crianças eram predominante narrativas. Embora o Modernismo brasileiro, entre as décadas de 1920 e 1940, tenha se mostrado fecundo no campo da poesia, essa fertilidade não se transferiu para a literatura infanto-juvenil, limitada quase que unicamente a $O$ menino poeta, de Henriqueta Lisboa (1901-1985), de 1943. Era de esperar, pois, que da poesia viesse o equivalente a Monteiro Lobato no âmbito da ficção, o que aconteceu em 1964, com Ou isto ou aquilo, de Cecília Meireles (1901-1963).

\section{Poesia para crianças}

Ou isto ou aquilo não foi o primeiro livro para crianças escrito por Cecília Meireles. Em 1937, ela lançou, em parceria com Josué de Castro (1908-1973), A festa das letras, cartilha que apregoa normas de higiene alimentar. Do mesmo ano é Rute e Alberto resolveram ser turistas, de cunho didático. Ou isto ou aquilo não é comparável a esses trabalhos preliminares, por não ter qualquer intuito educativo e por explorar, de modo inovador, a linguagem da poesia. "O vestido de Laura", um dos poemas do livro, ilustra a arte de Cecília:

O vestido de Laura

É de três babados,

Todos bordados. 
O primeiro, todinho,

Todinho de flores

De muitas cores.

No segundo, apenas

Borboletas voando,

Num fino bando.

O terceiro, estrelas,

Estrelas de renda

- talvez de lenda...

$O$ vestido de Laura

Vamos ver agora,

Sem mais demora!

Que as estrelas passam,

Borboletas, flores

Perdem suas cores.

Se não formos depressa,

Acabou-se o vestido

Todo bordado e florido!

[MEIRELES, 1979, p. 14]

O poema constitui-se de sete tercetos regulares, tendo o primeiro verso seis sílabas, o segundo, cinco, e o terceiro, quatro. As rimas são uniformes, ocorrendo entre as sílabas finais do segundo e do terceiro verso de cada estrofe. A simplicidade da linguagem, o uso de substantivos extraídos do cotidiano de uma menina, as frases curtas colaboram para a construção de um texto de fácil entendimento e grande sonoridade. Esses elementos permitem que o poema seja lido ou ouvido por crianças ou adultos, o que afiança sua comunicabilidade. Ao mesmo tempo, o tema mostra-se complexo: propicia o trânsito do mundo concreto, sinalizado pelos dois primeiros babados, citados na segunda e terceira estrofes, para a fantasia, identificada pelas estrelas "talvez de lenda..."; e expõe a efemeridade da existência, antecipada pela menção a flores e animais de vida breve, como a borboleta, e que motiva o carpe diem que sustenta o poema: "se não formos depressa / Acabou-se o vestido", sugerindo ao ser humano usufruir o pouco tempo de que dispõe.

Cecília Meireles ofereceu à poesia brasileira um estilo marcado pela leveza e musicalidade; e também uma perspectiva, segundo a qual os temas podem ser profundos e densos, capazes de transmitir ao ouvinte ou leitor um conhecimento de mundo. Poetas que vieram depois de Cecília e desejaram interagir com o público infantil - como Vinícius de Moraes (1913-1980), Sérgio Capparelli (1947), José Paulo Paes (1926-1998), Roseana Murray (1950) - aprenderam essa lição de poesia, consolidando o gênero entre as crianças e jovens de seu país. 


\section{Três reis}

Em 1974, é publicado O rei de quase-tudo, obra escrita e ilustrada por Eliardo França (1941). A narrativa, curta como uma pequena fábula, é protagonizada por um monarca que, dispondo de grande poder, nunca se contenta com suas posses, ambicionando sempre mais. Junta terras, dinheiro, os produtos da natureza, planetas e estrelas; mesmo assim, nunca está satisfeito, até descobrir que seus atos geraram tristeza, fealdade e dor. Decide devolver a seus legítimos donos o que conquistara, alcançando paz interior. Deixa, assim, de ser o "rei de quase-tudo", para ter "tudo". [FRANÇA, 1983, s. p.]

Entende-se por que a história traz as marcas da fábula: a personagem, anônima e designada apenas por seu lugar na ordem do Estado, passa por uma lição de vida, transmitida por tabela ao leitor. Além disso, "o rei de quase-tudo" pode representar vários tipos de pessoas, alcançando a generalidade prevista por aquele gênero. Como é um "rei”, pode representar as figuras que, no poder, desejam sempre mais; ou simbolizar o capitalismo, sistema econômico apoiado na acumulação de bens, pois agrega riquezas e propriedades; ou ainda, porque demonstra comportamento caprichoso, corresponder à criança mal-educada, que desconhece limites e precisa aprender a conviver com os outros.

O fato de conter características próprias à fábula não torna o livro pedagógico ou educativo, já que não conclui com uma "moral" que conduziria a interpretação e fecharia a narrativa em um sentido único. Pelo contrário, desde a leitura inicial, O rei de quase-tudo propicia uma compreensão aberta; além disso, propõe uma experiência com a qual o leitor se identifica por ter passado por situação semelhante. Sob este aspecto, privilegia a ótica de seu destinatário, procurando adaptar-se às suas necessidades. Aparecendo em um período em que faltavam narrativas desse tipo na literatura brasileira para a infância, tornou-se um marco reconhecido e premiado.

Dois outros reis seguiram-se a esse, sobressaindo-se no momento em que apareceram e deixando seus rastros na história subsequente da literatura infantil e juvenil brasileira. $\mathrm{O}$ primeiro deles é O reizinho mandão, de 1978, em que Ruth Rocha (1931), tal como Eliardo França, se utiliza de um gênero tradicional para discutir um tema contemporâneo. No caso de $O$ rei de quasetudo, o modelo europeu da fábula embasa o desenvolvimento da narrativa; em $O$ reizinho mandão, a literatura de cordel, modalidade poética de grande circulação no Nordeste brasileiro e de índole popular, sustenta o relato da trajetória do menino nascido na corte, herdeiro do trono e au- 
toritário, que, como todo "sujeitinho muito mal-educado", pensa ser "o dono do mundo". [ROCHA, 1984, p. 5.]

O reizinho mandão não é, pois, contado, e sim cantado, escolha importante, porque, na abertura, o narrador chama a atenção para as condições - todas impossíveis, como nas vezes em que o "atrás for na frente", o "prego for martelo" ou "cobra usar chinelo" - que podem fazer um cantador "se calar". O que está em jogo, pois, é a hipótese de alguém impedir a livre expressão das ideias, ação praticada pelo herói do título, o que provoca a infelicidade do povo. Advém da proibição o desejo de contestação, materializada pela menina que manifesta sua contrariedade, gritando, para todos ouvirem, que ninguém controla sua fala. A explosão de liberdade modifica a situação do reino, que redescobre a voz, impelindo o indesejado governante à fuga.

Ruth Rocha compartilha com Eliardo França o uso de uma figura comum das histórias de fadas - o rei que tudo pode, até um acontecimento interromper sua tirania por enquanto incontrolável. Na obra de Ruth Rocha, a alegoria política, latente na fábula de Eliardo, emerge com grande evidência, associando-se de imediato às condições que vivia o Brasil ao longo da década de 1970. O país fora vítima, em 1964, de golpe civil-militar que impusera um regime despótico, limitando drasticamente as liberdades civis, impunha a censura e reprimia os adversários por meio da violência e do arbítrio. Ao chamar a atenção para a importância de se rejeitar frontal e decisivamente essa situação, $O$ reizinho mandão expunha o desejo não apenas do público infantojuvenil, mas de toda sociedade, que lutava pelo reestabelecimento pleno da democracia.

Ao mesmo tempo, a obra, tal qual a de Eliardo França, suplanta aquele momento histórico, ao evidenciar que crianças e adultos "mandões" estão sempre presentes na vida cotidiana, e nunca é demais lembrar que a submissão gera silêncio e infelicidade. Tais temas, encontráveis no livro de Ruth Rocha, comprovam como a autora, que não se calou na época em que apresentou o livro, continua declarando, de modo eloquente, a inconformidade com as formas de dominação.

Um terceiro rei se distingue no mesmo período, só que divide a condição de protagonista com uma princesa. É o que ocorre em História meio ao contrário, de Ana Maria Machado (1941), publicado em 1979. O pano de fundo é, neste caso, o conto de fadas, berço onde nasceu e repousou a literatura infantil por muito tempo.

Em sua narrativa, a escritora brasileira parte do princípio exibido no título do livro: contrariará a tradição, porém, até certo ponto. Assim, a história começa pelo final, já que a frase de 
abertura - "e viveram felizes para sempre" [MACHADO, 1979, p. 4] - é a que usualmente fecha um conto de fadas. A partir daí, o relato acompanha o que ocorre ao casal que deveria viver feliz por toda a eternidade: o rei ignora o que ocorre fora dos muros de seu palácio, o que determina seus conflitos com o povo; e sua filha, a princesa, educada para sucedê-lo, recusa-se a ocupar um papel preestabelecido, preferindo construir, de modo independente, a própria história.

Provavelmente teria sido mais fácil para Ana Maria Machado escrever um enredo amparado pelos artifícios do gênero. Mas a solução de algibeira não a convinha, razão por que preferiu inovar, buscando alternativas para a narrativa que são, ao mesmo tempo, questionadoras e divertidas, agradando, pois, o leitor habituado aos contos de fadas. A contestação aparece sob vários ângulos: ao denunciar o alheamento dos responsáveis pelo poder, cegos para o que se passa fora de seu círculo; e ao sugerir que as pessoas, de preferência jovens, sigam o que manda o coração ou a inteligência, não, porém, obrigações ou mandados vindos de fora.

Publicado, como $O$ rei de quase-tudo e $O$ reizinho mandão, em uma época em que o Brasil estava submetido ao jugo de um governo ditatorial, História meio ao contrário manda um recado a crianças e adultos, estimulando a busca de uma existência autônoma, do ponto de vista pessoal, e a inconformidade, especialmente perante um sistema político autoritário e distanciado da população.

A obra de Ana Maria Machado sinalizava, na passagem dos anos 1970 para os 1980, que a literatura infantil não apenas se insubordinava contra o sistema vigente, fosse ele o literário, o político ou o econômico. Revelava igualmente que era hora de se fazer uma nova história, "meio ao contrário", porque, se dava seguimento ao que de melhor a literatura infantil fornecera até então, tinha, na mesma proporção, de procurar seu rumo e traçar os caminhos da estrada que se abria à frente, conforme uma aventura inovadora e plena de desafios.

\section{Excluídos e inadaptados}

Quando publicou Flicts, Ziraldo (1932) era um nome conhecido do público brasileiro. Criador, nos anos 1960, da Turma do Pererê, originalmente uma revista de quadrinhos, encantou a meninada com humor, variedade de personagens e inventividade das histórias, todas de sua lavra, incluindo enredo e ilustração.

Flicts desvela outra faceta do artista, não o desenhista da Turma do Pererê ou o mesmo o cartunista, que ocupava, desde o começo da década de 1960, as páginas de revistas femininas 
como Cláudia ou de jornais de contestação como O Pasquim, mas o pintor. Flicts é, primeiramente, um livro sobre as cores, como destaca a abertura, em que o narrador refere-se à personalidade do Vermelho, do Amarelo e do Azul, designados com letras maiúsculas, para afiançar que se trata de substantivos próprios, e não de adjetivos. Mas Flicts é igualmente um texto sobre a exclusão, já que o protagonista do título não encontra um lugar para ele: "Não existe no mundo nada que seja Flicts" [ZIRALDO, 1984, s. p.].

A busca do herói nasce do desejo de preencher essa carência, que significa descobrir o espaço que lhe compete no universo. As várias tentativas são seguidas de negação, aumentando o isolamento da personagem, que, no texto, é representado tão-somente por um nome, intraduzível, e uma cor. Não há seres vivos em Flicts, apenas cores e tons, combinando-se e, no entanto, recusando o protagonista, até ele sumir por completo. O desaparecimento, porém, é relativo: o narrador denuncia, na página final, que, sim, Flicts achou seu lugar, pois "a Lua é flicts".

Ao encerrar o relato, a cor sem dono transforma-se em adjetivo, porque encontrou sítio apropriado. Deixa então de ser personagem, para se converter em qualidade de um ser, alcançável se o vemos de perto, como ocorre, segundo o narrador, aos astronautas. É o que soluciona o conflito proposto pela história, solução mágica e também simbólica: o excluído revela ser o conteúdo mais profundo e secreto das coisas, conteúdo vazio, porém, porque compete ao leitor preenchê-lo com o sentido que lhe parecer mais adequado.

Flicts tornou-se, assim, metáfora não apenas do excluído, mas do reprimido que cada um deve aceitar, se quiser conviver melhor consigo mesmo. A riqueza das imagens tornou a narrativa paradigmática das possibilidades de representar o mundo interior das criaturas de modo compreensível, sem ser simplista. O sucesso da obra, que, em 2019, completa cinquenta anos, evidencia como Ziraldo soube atingir públicos de idades distintas e de vários períodos, no Brasil e no exterior. Por sua vez, sendo expressiva do emprego da cor e da qualidade gráfica de impressão, Flicts representa também o patamar de qualidade da ilustração da literatura infantil e juvenil brasileira, bem como de seu parque industrial, no âmbito da produção de livros, capaz de oferecer um bem durável, elaborado com gosto, de tamanho adequado e fácil de manusear.

O livro de Ziraldo inaugura rumos até então inusitados tanto para o gênero dirigido à infância e à juventude, quanto para a trajetória daquele artista, pois, a partir desse ponto, ele dedicar-se-á crescentemente à literatura para crianças e adolescentes, de que resultou outro importante 
marco - O menino maluquinho que, lançado em 1980, chegou, em 2010, à sua centésima edição, alcançando, naquele ano, a tiragem de quase três milhões de exemplares.

Flicts mostra ainda como expressar o mundo interior de uma criança para um leitor de pouca idade: é preciso encontrar formas de representação da intimidade, que se exteriorizem por meio de figuras de fácil tradução. A contribuição de Lygia Bojunga Nunes (1932) à história da literatura infantil brasileira advém de ela ter alcançado exibir, ao leitor, a criança por dentro, levando adiante a proposta contida no Flicts, de Ziraldo.

Lygia Bojunga Nunes estreou na literatura infantil em 1972 com Os colegas, obra antecipadora de várias características do texto da ficcionista que, dez anos depois, viria a receber um prêmio literário consagrador, o Hans Christian Andersen. Uma dessas marcas é a abertura, que vai direto ao ponto, como no trecho reproduzido a seguir:

No princípio eram só dois. Tinham se encontrado pela primeira vez revirando a mesma lata de lixo.

- Esse osso que tem aí é meu!

- É meu!

- Já disse que é meu! [NUNES, 1979, p. 9]

O narrador parece não fugir a um padrão da literatura infantil, iniciando a narrativa pela cronologia. Só que o "era uma vez", índice da atemporalidade do mito ou do conto de fadas, converte-se em "princípio", sinal de que a história começa no presente. Daí para frente, o estilo só pode mudar radicalmente: não há caracterização prévia das personagens, e ninguém explica ao leitor que se trata de dois cães. É o diálogo que encaminha o destinatário para a compreensão do que acontece, exigindo dele comprometimento com a leitura e, simultaneamente, maior liberdade de ação. $\mathrm{O}$ estilo implica agilidade por parte do narrador, rapidez na comunicação e interação com o leitor, atributos que desenham o relacionamento da escritora com a literatura infantil e com suas expectativas perante o público.

Os dois cães da abertura da história não formam as figuras exclusivas da história. Aos poucos, eles encontram outros animais que, por alguma razão, estão marginalizados ou sentem-se infelizes, vindo a agregar-se ao grupo de amigos, de que nasce um conjunto musical. Eis a segunda característica de Os colegas, desenvolvida em outras narrativas da escritora: as personagens, como Flicts, estão em busca de lugar na sociedade, que resulta - e essa é a peculiaridade da temática de Lygia - da descoberta da vocação artística. Os colegas são cantores; Angélica, do livro com esse título, de 1975, faz teatro; Raquel, de A bolsa amarela, de 1976, escreve; Maria, de 
Corda bamba, de 1979, seguindo a carreira dos pais, é equilibrista em um circo. A arte é, pois, fator importante para a liberação das personagens, escolha que se coaduna com o teor dos livros que elas protagonizam, já que também as obras provam-se inovadoras e inconformadas com a tradição da literatura infantil.

Angélica, posterior a Os colegas, não narra apenas a história da cegonha que se descobre artista, rompendo com os padrões predeterminados esperáveis dela. Animal em princípio previsível e previamente destinado a preencher um papel no imaginário ocidental, a cegonha é uma figura de quem não se esperam novidades ou interrogações sobre a função a desempenhar no conjunto do arranjo social. É o que Angélica rejeita, na busca da identidade. Ao lado dela, desenvolvese uma segunda personagem, o porco Porto, cuja história denota maior complexidade interior: não se conforma com a aparência, a ponto de fugir de casa, alterar o nome e tentar escapar a seu fado.

Sua trajetória corresponde à inversão desse projeto, pois ele tem de trilhar o caminho de volta: ao contrário de Angélica, para o pequeno porco, descobrir a identidade é aceitar-se como tal, e esse é um difícil itinerário. Para tanto, a convivência com a cegonha rebelde é importante, porque significa o encontro do amor e da autoconfiança. Ao lado disso, Porto conhece seu pendor artístico, e a possibilidade de se expressar por intermédio da criação dramática conclui o processo de liberação interior.

A bolsa amarela, de 1976, parece completar uma trilogia, porque também narra o percurso de uma personagem na direção da segurança pessoal e da criatividade. Por sua vez, processase uma alteração: Raquel é uma menina, de modo que o mundo da criança passa a ser traduzido por uma pessoa, e não mais por um animal, a simbolizar comportamentos ou problemas íntimos. A mudança não tem apenas cunho externo, pois indica outra forma de compreender o papel da literatura infantil e ocorre em um momento em que os escritores procuram alternativas eficazes para a consolidação da escrita consagrada ao público mirim.

Para adentrar o universo íntimo de Raquel e expressá-lo, Lygia vale-se de uma simbologia poderosa que marcou época na literatura infantil e juvenil. O primeiro desses símbolos é a bolsa do título, imagem do inconsciente da garota, onde ela guarda seus traumas, a serem superados como modo de a protagonista alcançar tranquilidade e dar vazão à sua propensão artística. Assim, A bolsa amarela comporta essa importante inovação: as inseguranças e temores de Raquel sobem 
para o primeiro plano, traduzidos por suas palavras ou pelos objetos que a menina, compulsivamente, carrega consigo, dentro da mítica bolsa.

É como se Lygia apontasse ser possível desvendar o universo interior da criança, por esse ter um conteúdo próprio, com imagens e aspirações, impossíveis de serem simplesmente reduzidas a noções de psicologia infantil ou de psicanálise. A via de criação inaugurada pela escritora revelou-se fértil, vindo a ser percorrida por Vivina de Assis Viana (1940), em O dia de ver meu pai, de 1977, e Joel Rufino dos Santos (1941), em O curumim que virou gigante, de 1980.

Entre 1964, ano da publicação de Ou isto ou aquilo, de Cecília Meireles, e 1979, quando Ana Maria Machado apresentou sua História meio ao contrário, apenas quinze anos se passaram. Contudo, a literatura infantil e juvenil já não era a mesma de antes. Com livros como $O$ reizinho mandão, aprendera a discutir temas de forte apelo político, que envolviam adultos e crianças; com $O$ rei de quase tudo, Flicts ou A bolsa amarela, soubera incorporar ao gênero a interioridade de seu leitor, valendo-se de recursos visuais, gráficos e simbólicos.

Ao lado desses novos caminhos, a poesia descobrira sua linguagem própria, formulando um diálogo constante com os pequenos destinatários. E formatos tradicionais eram questionados, como fizeram, antes, ao mesmo tempo ou depois do trabalho de Ana Maria Machado, criadores como Fernanda Lopes de Almeida, autora de A fada que tinha ideias, de 1971, Bartolomeu Campos Queirós (1944-2012), com Onde tem bruxa, tem fada, de 1979, ou Pedro Bandeira (1942), em O fantástico mistério de Feiurinha, de 1986.

A eventualidade do retrocesso estava fora de questão, hipótese confirmada nas décadas seguintes, com o incremento da produção de livros para crianças e jovens, o crescimento do número de autores e ilustradores, os investimentos públicos e privados na área. Nas primeiras décadas deste novo milênio, a literatura infantil e juvenil brasileira apresenta-se como mercado pujante, estimulando a criatividade e a experimentação de autores, ilustradores e editores, e colaborando positivamente tanto para a formação saudável de seus leitores, quanto para a profissionalização dos seus agentes, cenário favorável decorrente da contribuição notável dos expoentes aqui destacados.

\section{Referências}

FRANÇA, Eliardo. O rei de quase-tudo. 7. ed. Rio de Janeiro: Orientação Cultural, 1983. 
Machado, Ana Maria. História meio ao contrário. São Paulo: Ática, 1979.

MeIREles, Cecília. Ou isto ou aquilo. 3. ed. Rio de Janeiro: Civilização Brasileira, 1979.

NunES, Lygia Bojunga. Os colegas. 5. ed. Rio de Janeiro: J. Olympio, 1979.

RochA, Ruth. O reizinho mandão. 4. ed. São Paulo: Pioneira, 1984.

ZIRALDO. Flicts. 16. ed. São Paulo: Melhoramentos, 1984.

Recebido em 05 de novembro de 2019. Aceito em 15 de novembro de 2019. 